\title{
Adolescent nonsuicidal self-injury: Examining the role of child abuse, comorbidity, and disinhibition
}

\section{Citation}

Auerbach, Randy P., Judy C. Kim, Joanna M. Chango, Westley J. Spiro, Christine Cha, Joseph Gold, Michael Esterman, and Matthew K. Nock. 2014. "Adolescent Nonsuicidal Self-Injury: Examining the Role of Child Abuse, Comorbidity, and Disinhibition." Psychiatry Research 220 (1-2) (December): 579-584. doi:10.1016/j.psychres.2014.07.027.

\section{Published Version}

doi:10.1016/j.psychres.2014.07.027

\section{Permanent link}

http://nrs.harvard.edu/urn-3:HUL.InstRepos:33461782

\section{Terms of Use}

This article was downloaded from Harvard University's DASH repository, and is made available under the terms and conditions applicable to Open Access Policy Articles, as set forth at http:// nrs.harvard.edu/urn-3:HUL.InstRepos:dash.current.terms-of-use\#OAP

\section{Share Your Story}

The Harvard community has made this article openly available.

Please share how this access benefits you. Submit a story.

\section{Accessibility}




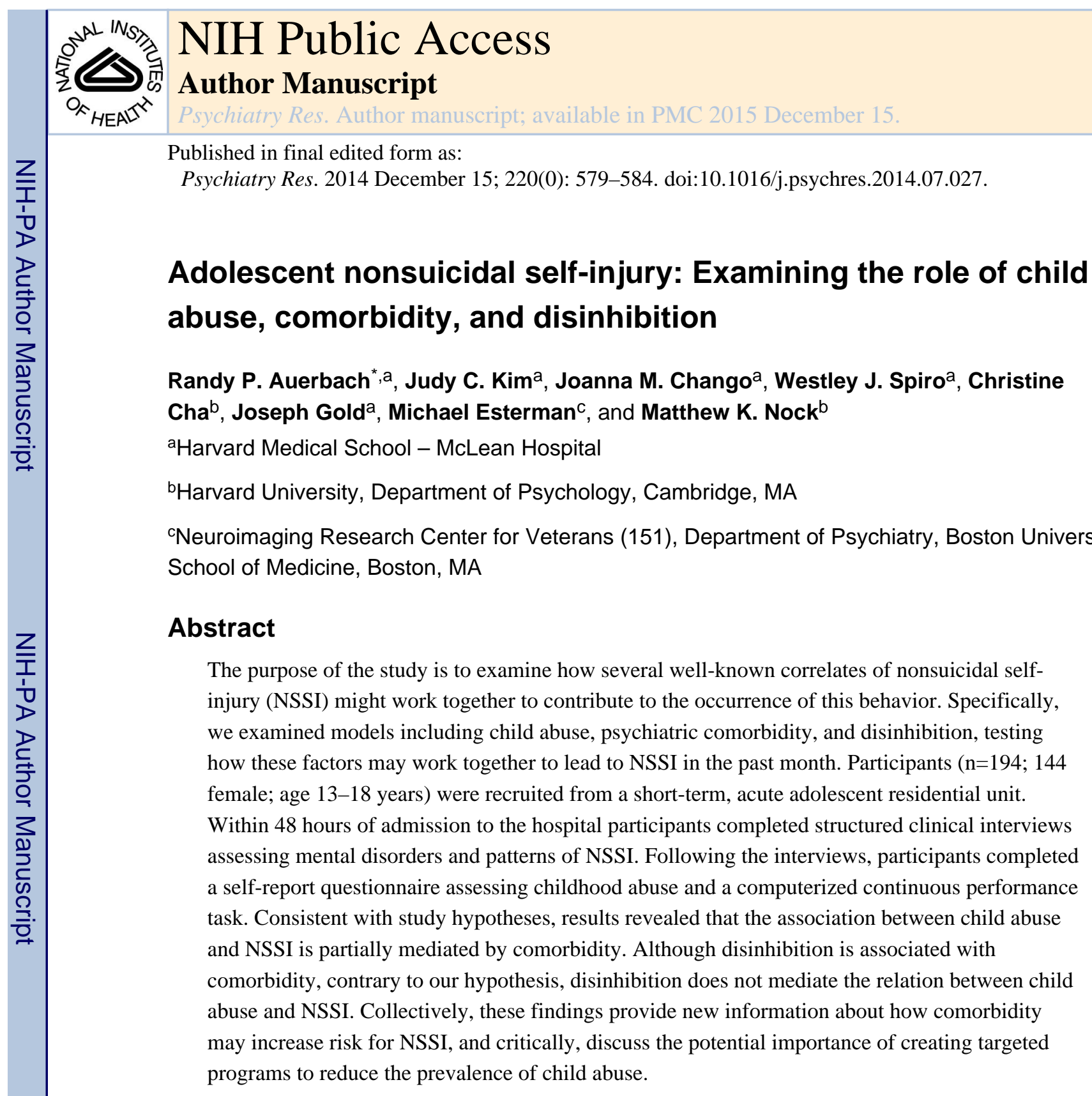

\section{Keywords}

Nonsuicidal Self-Injury; Comorbidity; Disinhibition; Impulsivity; Child Abuse

C 2014 Elsevier Ireland Ltd. All rights reserved.

Please send all correspondence to Randy P. Auerbach: rauerbach@mclean.harvard.edu; Center for Depression, Anxiety and Stress Research, Child and Adolescent Mood Disorders Laboratory, 115 Mill Street, de Marneffe, Room 240, Belmont, MA 02478; Tel. (617) 855-4405; Fax. (617) 855-4231.

Publisher's Disclaimer: This is a PDF file of an unedited manuscript that has been accepted for publication. As a service to our customers we are providing this early version of the manuscript. The manuscript will undergo copyediting, typesetting, and review of the resulting proof before it is published in its final citable form. Please note that during the production process errors may be discovered which could affect the content, and all legal disclaimers that apply to the journal pertain. 


\section{Introduction}

Nonsuicidal self-injury (NSSI), the intentional destruction of one's body tissue without an intent to die, typically begins in early adolescence, and prevalence rates are approximately 13 to $23 \%$ in adolescent community samples (Jacobson and Gould, 2007; Nock, 2009) and $40 \%$ among adolescent inpatients (Klonsky and Muehlenkamp, 2007). As 50 to $75 \%$ of individuals reporting NSSI make a suicide attempt during their life course (Nock et al., 2006), understanding the factors that may lead to NSSI in youth is a pressing public health concern. The developmental unfolding of NSSI is likely equifinal, with a number of developmental and psychiatric factors shown to be predictive of NSSI (Klonsky, 2007; Nock, 2009). However, little is known about how these different risk factors may work together to produce NSSI. In the current manuscript, we examine the role of three potential correlates of adolescent NSSI: child abuse, psychiatric comorbidity, and disinhibition.

\subsection{Disentangling the associations among child abuse, comorbidity, disinhibition, and NSSI}

Child abuse is a strong predictor of adolescent NSSI; however, the specific pathways through which abuse may lead to NSSI are unclear (Nock, 2009). From a developmental perspective, early life adversity negatively affects neurogenesis, synaptic production and pruning, and myelination during developmentally sensitive periods, which impacts both structural and functional development within discrete areas of the brain (Teicher et al., 2003). These neurobiological consequences may contribute to the onset and maintenance of psychopathology in youth (Widom et al., 2007), and alternatively, abuse-related abnormalities, particularly within the amygdala and corpus callosum, may compromise executive functioning increasing the likelihood that adolescents act impulsively (Allman et al., 2001; Jollant et al., 2007; Lara and Akiskal, 2006; Monkul et al., 2007). Taken together, there may be two separate, but related, paths in which child abuse may lead to NSSI behaviors.

One possible pathway is that child abuse contributes to greater comorbidity, and greater comorbidity leads to adolescent NSSI behaviors. Specifically, child abuse contributes to the onset of depressive (Brown et al., 1999), anxiety (e.g., PTSD - Kingston and Raghavan, 2009; panic disorder - Goodwin et al., 2005), and personality (e.g., borderline personality disorder - Gunderson, 2009) disorders in youth. Widom and colleagues (2007) also have found that child maltreatment is associated with greater comorbidity in youth and young adults. Such psychiatric comorbidity stems, in part, from the fact that individuals with a history of maltreatment rarely experience a single traumatic event. Rather, these individuals typically experience several episodes, often across different types of abuse (i.e., emotional, physical, and sexual; Kessler, 2000), and Cloitre et al. (2009) assert that repeated or prolonged exposure to maltreatment results in a complex symptom presentation, especially as it relates to deficits regarding anxiety, anger, aggression, and avoidant behaviors.

Recent research has also explored clinical diagnostic correlates of NSSI, and although many think of NSSI as occurring primarily in the context of borderline personality disorder, studies have revealed that NSSI occurs in a wide range of mental disorders (Nock et al., 2006; Glenn and Klonsky, 2013). At the same time, psychiatric comorbidity appears to be 
the rule rather than the exception as the National Comorbidity Survey reports that $79 \%$ of psychiatric diagnoses in individuals with at least one lifetime psychiatric diagnosis were comorbid with other diagnoses (Kessler et al., 1994). Adolescent comorbidity negatively impacts cognitive (e.g., executive functioning, attention), physical (e.g., weight gain, fatigue), psychological (e.g., self-worth), and behavioral (e.g., persistence, motivation) functioning (e.g., Lewinsohn et al., 1995; Patel et al., 2007), and for some, these broadbased deficits may increase overall distress. In other cases, however, the difficulty of managing an intense range of symptoms coupled with associated interpersonal stress and academic decline, commonly present in the context of adolescent psychopathology, may foster feelings of helplessness and hopelessness (e.g., Abela et al., 2006; Auerbach et al., 2010). Some, but not all, adolescents may utilize NSSI to provide short-term relief from this distress (Nock, 2009). Consequently, we hypothesized that child abuse would predict greater psychiatric comorbidity, and moreover, psychiatric comorbidity may be associated with adolescent NSSI.

Alternatively, as child abuse negatively affects psychobiological circuits implicated in impulsiveness (Braquehais et al., 2010), such abuse may increase impulsiveness, which then leads to adolescent NSSI behaviors. Interestingly, people who engage in NSSI have higher self-report of impulsivity than non-injurers; however, behavioral and biological tests of various dimensions of impulsiveness have failed to find any such differences (Simeon et al, 1992; c.f., Dougherty et al., 2009; Janis and Nock, 2009; Glenn and Klonsky, 2010). A majority of this research has examined these differences without considering the impact of child abuse, and as noted earlier, child abuse negatively impacts the development of both the corpus collosum and the amygdala (Braquehais et al., 2010). This is of particular import as the corpus collusum is responsible for interhemispheric communication, while the amygdala is implicated in modulating arousal. Taken together, decreased hemispheric integration of information within the corpus collosum and hyperreactivity in the amygdala may lead to greater disinhibition - a subdomain of impulsiveness that reflects acting without thinking (Reynolds et al., 2006). Historically, performance-based indices of disinhibition have not demonstrated differences among self-injurers and non-injurers. Nevertheless, based on mounting neurobiological research (e.g., Teicher et al., 2003), we hypothesized that child maltreatment may compromise neural circuitry that modulates disinhibition, as assessed through a performance-based task, and thus, resulting disinhibition may mediate the relationship between child abuse and adolescent NSSI behaviors.

\subsection{Goals of the current study}

Although there are many known risk factors associated with NSSI behaviors in youth, child abuse, disinhibition, and comorbidity are well-known correlates of NSSI behaviors that are also strongly associated with each other (e.g., Widom et al., 2007; Janis and Nock; Nock, 2009). We first tested whether those with a history of NSSI score higher on measures of these constructs. Next, we tested whether greater comorbidity mediates the association between past child abuse and NSSI frequency in the past month. Finally, we tested whether greater disinhibition mediates the association between child abuse and NSSI frequency in the past month. 


\section{Method}

\subsection{Participants}

Participants in this study were recruited from an acute adolescent residential treatment program within the greater Boston area and included 194 adolescents (50 male, 144 female) with ages ranging from 13 to 18 (Mean $=15.53, \mathrm{SD}=1.34$ ). The ethnic distribution included: $77.2 \%$ Caucasian, 9.8\% Asian, $8.3 \%$ multicultural (i.e., greater than one race endorsed), 3.6\% Black, 0.5\% Native American, and 0.5\% Native Hawaiian or Other Pacific Islander.

\subsection{Procedure}

The Institutional Review Board provided approval for this study, and the treatment of participants was in accordance with American Psychological Association ethical standards. Prior to participation, legal guardians and adolescents aged 18 years provided consent to participate, and adolescents aged 12-17 provided assent. During the hospital admission procedures, all individuals were explained the overarching aims of the current study, and all individuals were encouraged to participate. However, given privacy issues, study staff did not explore reasons of non-participation. The response rate was $72.1 \%$. Within 48 hours of admission to the hospital, participants completed two structured clinical interviews assessing psychopathology and patterns of self-harm and suicidality. Following the interviews, participants completed a computerized continuous performance task, and then, participants completed a self-report questionnaire assessing past childhood abuse.

\subsection{Instruments}

2.3.1. Childhood Trauma Questionnaire (CTQ) (Bernstein et al., 1994)—The CTQ is a 25-item self-report instrument designed to assess adolescents' experience of abuse and neglect in childhood. We examined the role of physical, sexual, and emotional abuse, and subscales pertaining to neglect were not utilized as prior research suggests that abuse is more strongly associated with NSSI (Glassman et al., 2007) Participants are instructed to answer each item based on their experiences growing up as a child or teenager and to rate each item on a 5-point scale ranging from 1 (never true) to 5 (very often true), with higher scores reflecting more self-reported child abuse. A total abuse score was created by summing subscales pertaining to physical, sexual, and emotional abuse (i.e., 15-items). Past research has demonstrated strong reliability and validity (Bernstein et al., 1997) In the current study, internal consistency for the total abuse scale (i.e., emotional, physical, and sexual abuse) was strong (Cronbach's $a=0.89$ ).

\subsubsection{Mini International Neuropsychiatric Interview for Children and Adolescents (MINI-KID) (Sheehan et al., 2010)—The MINI-KID is a structured} diagnostic interview used to assess current and past psychopathology in youth. Interviews were administered by trained research assistants to adolescent participants. Prior to administration, research assistants received approximately 25 hours of training. In the current study, the number of diagnosed psychopathological disorders among adolescents ranged from $0-8$ with higher scores corresponding to a greater total number of clinical disorders $($ Mean $=2.79, \mathrm{SD}=1.58$ ). The MINI-KID has previously shown good reliability 
and validity in diagnosing psychiatric disorders in children and adolescents (Sheehan, et al., 2010).

2.3.3. Gradual Onset Continuous Performance Task (gradCPT) (Esterman et al., 2012)—Disinhibition was assessed using the gradCPT. Adolescents viewed randomly presented gray scale photographs of mountain scenes (10\%) and city scenes (90\%). The images gradually transition from one to the next, using a linear pixel-by-pixel interpolation, with each transition occurring over $800 \mathrm{~ms}$. Images were presented to participants with Matlab using the Psychtoolbox extensions. Participants completed two 30-second practice blocks, followed by a single 6-minute block containing 450 trials. Participants were instructed to respond to the visual target (e.g., city scenes) by pressing a computer key and withhold a response to the non-target (e.g., mountain scenes). Correct omissions were defined as when participants correctly inhibited responding (e.g., pressing a computer key) to mountain scenes, and commission errors occurred when participants incorrectly responded to mountains. Disinhibition was measured using commission error rate during the 6-minute task.

\subsubsection{Self-Injurious Thoughts and Behaviors Interview (SITBI) (Nock et al.,} 2007)—The SITBI is a structured clinical interview that assesses the presence, frequency, severity, age-of-onset, and other characteristics of suicidal thoughts and behaviors and NSSI thoughts and behaviors. The current study assessed the frequency of whether adolescents reported NSSI thoughts (i.e., thoughts pertaining to the intentional destruction of one's bodily tissue without the intent to die) and/or behaviors (i.e., intentional destruction of one's bodily tissue without the intent to die) in the past month using responses from the item, "How many times in the past month have your purposely hurt yourself without wanting to die?" and "How many days in the past month have you thought about hurting yourself without wanting to die?"

\subsection{Data analysis}

Descriptive statistics and between-group analyses for self-injurers and non-injurers were conducted to examine mean differences in hypothesized independent variables and potential mediators. Additionally, to examine the hypothesized mediation models for the sample as a whole, Sobel tests were utilized to estimate the significance of the mediation effects (Goodman, 1960; Sobel, 1982; Baron and Kenny, 1986; MacKinnon, Warsi, and Dwyer, 1995). In these models, path a denotes the pathway between the independent variable and mediator, path $b$ delineates the link between the mediator and dependent variable, path $c$, the direct effect, reflects the pathway between the independent variable and the dependent variable. Path c' was estimated by controlling for the proportion of variance accounted for by the indirect effects (i.e., path ab). We used PROC GENMOD in SAS with a loglinear model and Poisson distribution, which accounts for the positive skew of our dependent variable (i.e., frequency of NSSI behaviors), to calculate the path coefficients and standard errors of those path coefficients. The path coefficients and standard errors were then used to calculate the critical ratio to test the significance of the indirect effect. The mediation model is considered significant if the indirect effect of the independent variable on the dependent variable via the mediator is significantly different from zero. 


\section{Results}

\subsection{Descriptive statistics}

Pearson correlations and descriptive statistics for self-injurers $(n=157)$ versus non-injurers $(\mathrm{n}=37)$ are presented in Table 1 . We examined these associations separately between selfinjurers and non-injurers as a means of determining whether the strength of the associations differed markedly between the two groups. Among self-injurers, correlation analyses suggest that number of psychiatric diagnoses is positively associated with levels of early childhood abuse and current disinhibition, and similarly, for non-injurers, higher levels of disinhibition are associated with greater comorbidity. Means, standard deviations, and ranges of NSSI thoughts and behaviors in the past month are provided in Table 2. When examining the NSSI mode, self-injurers reported the following: (a) cut or carved skin ( $\mathrm{n}=$ $151 ; 96.18 \%$ ), (b) scraped skin to the point of drawing blood ( $\mathrm{n}=82 ; 52.23 \%)$, (c) hit self on purpose ( $\mathrm{n}=81 ; 51.59 \%)$, (d) picked areas of the body to the point of drawing blood ( $\mathrm{n}=$ $75 ; 47.77 \%)$, (e) burned skin (i.e., with a cigarette, match, or hot object) $(\mathrm{n}=53 ; 33.76 \%)$, and (f) inserted sharp objects into skin or nails $(\mathrm{n}=50 ; 31.85 \%)$. Independent sample $t$ tests examining NSSI as a function of gender found that there were no gender differences in number of NSSI thoughts $(t(165)=-1.77, p=0.08$, Cohen's $\mathrm{d}=-0.35)$ and NSSI behaviors $(t(93.24)=-1.65, p=0.10$, Cohen's $\mathrm{d}=-0.22)$ in the past month.

\subsection{Between-group analyses}

Independent sample $t$ tests revealed that relative to non-injurers $(\mathrm{n}=37)$, self-injurers $(\mathrm{n}=$ 157) report a higher level of total child abuse $(t(89.26)=-4.53, p<0.0001$, Cohen's $\mathrm{d}=$ $-0.61)$ and sexual abuse $(t(154.61)=-5.52, p<0.0001$, Cohen's $d=-0.50)$ but not physical abuse $(t(188)=-0.41, p=0.68$, Cohen's $d=-0.08)$. Additionally, in comparison to noninjurers, self-injurers also report a greater number of psychiatric diagnoses $(t(192)=-5.04$, $p<0.0001$, Cohen's $\mathrm{d}=-0.93$ ) (see Table 3 ) and NSSI thoughts in the past month $(t(165)=$ $-5.85, p<0.0001$, Cohen's $d=-0.99)$. Self-injurers do not differ from non-injurers in levels of disinhibition $(t(187)=-1.58, p=0.11$, Cohen's $d=-0.30)$.

\subsection{Comorbidity as a mediator between child abuse and NSSI frequency}

We first examined whether a greater number of clinical diagnoses mediates the relationship between child abuse and NSSI frequency in the past month (Figure 1A). The direct effect between child abuse and NSSI frequency in the past month is significant (path $\mathbf{c}: b=0.015$, $\mathrm{SE}=0.003, p<0.0001$ ). Additionally, childhood abuse positively predicts the number of clinical diagnoses (path a: $b=0.018, \mathrm{SE}=0.004, p<0.0001$ ), and number of diagnoses, in turn, predicts the frequency of NSSI behaviors in the past month (path b: $b=0.263$, SE $=$ $0.017, p<0.0001)$. After accounting for the variance in diagnostic comorbidity, the effect of child abuse on NSSI frequency in the past month is significant (path c': $b=-0.0006, \mathrm{SE}=$ $0.003, p=0.845$ ). Importantly, the test of the indirect effect (path ab: $b=4.32, \mathrm{SE}=0.001$, $p<0.0001$ ) indicates that the greater comorbidity mediates the relationship between child abuse and the frequency of NSSI behaviors in the past month. ${ }^{1}$ 


\subsection{Disinhibition as a mediator between child abuse and NSSI frequency}

Next, we examined whether disinhibition mediates the relationship between early childhood abuse and occurrence of NSSI frequency in the past month (Figure 1B). Results reveal that the direct effect between abuse and NSSI behaviors in the past month is significant (path c: $b=0.015, \mathrm{SE}=0.003, p<0.0001)$. However, greater abuse does not significantly impact disinhibition (path a: $b=0.004, \mathrm{SE}=0.014, p=0.764$ ). Although the bivariate correlation between disinhibition and NSSI was non-significant $(r=.10$; see Table 1$)$, in this mediation model that included non-injuring participants, higher levels of disinhibition were associated with frequency of NSSI behaviors in the past month (path $\mathbf{b}: b=1.36, \mathrm{SE}=0.173, p<$ 0.0001). Further, after accounting for disinhibition, the direct effect between abuse and NSSI behaviors in the past month is not significant (path c': $b=0.01, \mathrm{SE}=0.003, p<$ 0.0001 ). The test of the indirect effect of disinhibition on the relationship between abuse and NSSI frequency in the past month is not significant (path ab: $b=0.285, \mathrm{SE}=0.019, \mathrm{p}=$ 0.78 ). Thus, our findings suggest that greater disinhibition does not mediate the relation between childhood abuse and NSSI behaviors in the past month.

\section{Discussion}

In light of alarming epidemiological data regarding the prevalence of NSSI among adolescents (Jacobson and Gould, 2007; Klonsky and Muehlenkamp, 2007), the current study examined two mediation models aimed at starting to understand how different risk factors may lead to NSSI frequency. We tested whether comorbidity and disinhibition mediated the relationship between child abuse and the frequency of NSSI behaviors in the past month. These mediation models provide a framework to unpack the developmental chain that may contribute to NSSI frequency, and consistent with our hypotheses, results indicate that: (a) comorbidity partially mediates the relation between child abuse and NSSI, whereas (b) disinhibition does not.

\subsection{Adolescent nonsuicidal self-injury: What role does psychiatric comorbidity play?}

Child abuse is associated with greater comorbidity, and number of diagnoses, in turn, predicts NSSI frequency. One insidious consequence of child abuse is the development of complex, comorbid psychopathology, which has profound clinical consequences. For example, among depressed adolescents, the presence of comorbidity is associated with greater social dysfunction, more severe depressive symptoms, longer duration of depressive episodes, and a greater frequency of suicide attempts, and critically, these findings also are reflected across other mental health disorders (see Lewinsohn et al., 1995). Managing and attending to these diverse array of psychiatric symptoms (and associated problems) may generate significant distress, and for some youth, NSSI may provide a dysfunctional means of regulating their distress (see Nock, 2009).

Alternatively, although adolescent comorbidity is associated with a greater utilization of mental health services (Rohde et al., 1991), such comorbidity is less likely to respond

\footnotetext{
${ }^{1}$ Between-group comparisons suggest that relative to non-injurers, self-injurers report higher levels of sexual but not physical abuse. Consequently, we estimated models with and without physical abuse, and the model remained significant whether physical abuse was included or excluded.
} 
optimally to psychotherapy or medication (e.g., Curry et al., 2006). Failed treatment experiences are challenging, and it is not uncommon for adolescents to internalize these experiences - believing that it is both their fault and feeling as though their condition is beyond hope. These experiences may contribute to feelings of helplessness or hopelessness, and for certain adolescents, NSSI may offer a greater sense of control over their pain and symptoms.

\subsection{Child abuse, disinhibition, and nonsuicidal self-injury}

In contrast to our hypothesis, disinhibition did not mediate the relationship between child abuse and NSSI frequency. One possibility for our null findings is that past research suggests that the type and time of abuse differentially affects neurobiological development (Andersen et al., 2008). Andersen and colleagues (2008) have demonstrated that repeated sexual abuse occurring during developmentally sensitive periods is associated with alterations in regional brain size. Not surprisingly, these important developmental differences likely have a profound effect on behavioral functioning. Consequently, examining the relationship between past child abuse and disinhibition may require using a more fine-grained approach. Future research would benefit from acquiring a more detailed chronology and description of past abuses especially as this information may better inform the developmental unfolding of disinhibition and subsequent NSSI.

\subsection{Limitations}

There are a number of important limitations in our approach. First, while we examine NSSI in the past month, the study is cross-sectional. Future research is warranted to determine whether our models prospectively predict NSSI among adolescents. Second, we used a selfreport instrument to assess child abuse, which has inherent biases. A more rigorous assessment of child abuse would include an interview as well as external confirmation, and moreover, would assess the type and timing of abuse, which has been shown to differentially impact neurobiological development (Andersen et al., 2008). Third, there are more female as opposed to male participants (50 male versus 144 female). This discrepancy reflects psychopathological prevalence differences in adolescence, and thus, the sampling may impact the generalizability of our findings. Additionally, as the sample was recruited through the hospital, there is a relatively small sample of non-injurers to self-injurers, which again, makes certain between-group comparisons more challenging. Fourth, while recent research has found a strong relationship between adolescent borderline personality disorder and NSSI behaviors (Nock et al, 2006), the current study did not assess personality disorders in youth. Unfortunately, this limits our capacity to examine the relative contribution of internalizing/externalizing versus personality disorders with respect to patterns of NSSI behaviors among adolescence. Last, the current study assessed the frequency of NSSI thoughts and behaviors, however, such an approach does not allow for the meaningful investigation of NSSI Disorder. Rather, NSSI Disorder is more than examining the frequency of thoughts and behaviors, and it is critical to explore NSSI in the context of functional expectations, difficulties associated with these behaviors, and clinical consequences. A thorough investigation of these factors will, ultimately, lead to a richer understanding of why certain youth hurt themselves. 


\subsection{Clinical implications}

Adolescent NSSI is not specific to a particular psychopathology, but rather, it is associated with a wide range of mental health disorders. Our findings underscore the importance of attending to abuse earlier within the developmental course, and once identified, carefully assessing the presence of comorbidity and NSSI. These findings also support the importance of improving our efforts to prevent abuse. Indeed, educational programs discussing the developmental sequela of abuse as well as outlining early warning signs that may arise from abuse may help disrupt a path that includes abuse, comorbidity, and subsequent NSSI behaviors.

\section{Acknowledgments}

Support was provided by the Simches Fund, Tommy Fuss Fund, and NIMH K23MH097786. We sincerely thank the Adolescent Residential Treatment staff at McLean Hospital for their ongoing collaboration, time, and efforts.

\section{References}

Abela JR, Aydin C, Auerbach RP. Operationalizing the "vulnerability" and "stress" components of the hopelessness theory of depression: a multi-wave longitudinal study. Behaviour Research and Therapy. 2006; 44(11):1565-1583. [PubMed: 16458851]

Allman JM, Hakeem A, Erwin JM, Nimchinsky E, Hof P. The anterior cingulate cortex. Annals of the New York Academy of Sciences. 2001; 935(1):107-117. [PubMed: 11411161]

Andersen SL, Tomada A, Vincow ES, Valente E, Polcari A, Teicher MH. Preliminary evidence for sensitive periods in the effect of childhood sexual abuse on regional brain development. The Journal of Neuropsychiatry and Clinical Neurosciences. 2008; 20(3):292-301. [PubMed: 18806232]

Auerbach RP, Eberhart NK, Abela JR. Cognitive vulnerability to depression in Canadian and Chinese adolescents. Journal of Abnormal Child Psychology. 2010; 38(1):57-68. [PubMed: 19669872]

Baron RM, Kenny DA. The moderator-mediator variable distinction in social psychological research: conceptual, strategic, and statistical considerations. Journal of Personality and Social Psychology. 1986; 51(6):1173-1182. [PubMed: 3806354]

Bernstein DP, Ahluvalia T, Pogge D, Handelsman L. Validity of the Childhood Trauma Questionnaire in an adolescent psychiatric population. Journal of the American Academy of Child Adolescent Psychiatry. 1997; 36(3):340-348. [PubMed: 9055514]

Bernstein DP, Fink L, Handelsman L, Foote J, Lovejoy M, Wenzel K, Ruggiero J. Initial reliability and validity of a new retrospective measure of child abuse and neglect. The American Journal of Psychiatry. 1994; 151(8):1132-1136. [PubMed: 8037246]

Braquehais MD, Oquendo MA, Baca-García E, Sher L. Is impulsivity a link between childhood abuse and suicide? Comprehensive Psychiatry. 2010; 51(2):121-129. [PubMed: 20152291]

Brown J, Cohen P, Johnson JG, Smailes EM. Childhood abuse and neglect: Specificity of effects on adolescent and young adult depression and suicidality. Journal of the American Academy of Child \& Adolescent Psychiatry. 1999; 38(12):1490-1496. [PubMed: 10596248]

Cloitre M, Stolbach BC, Herman JL, van der Kolk B, Pynoos R, Wang J, Petkova E. A developmental approach to complex PTSD: Childhood and adult cumulative trauma as predictors of symptom complexity. Journal of Traumatic Stress. 2009; 22(5):399-408. [PubMed: 19795402]

Curry J, Rohde P, Simons A, Silva S, Vitiello B, Kratochvil C. Predictors and moderators of acute outcome in the Treatment for Adolescents with Depression Study (TADS). Journal of the American Academy of Child \& Adolescent Psychiatry. 2006; 45(12):1427-1439. [PubMed: 17135988]

Dougherty DM, Mathias CW, Marsh-Richard DM, Prevette KN, Dawes MA, Hatzis ES, Nouvion SO. Impulsivity and clinical symptoms among adolescents with non-suicidal self-injury with or without attempted suicide. Psychiatry Research. 2009; 169(1):22-27. [PubMed: 19631392] 
Esterman M, Noonan SK, Rosenberg M, Degutis J. In the zone or zoning out? Tracking behavioral and neural fluctuations during sustained attention. Cerebral Cortex. 2013; 23(11):2712-2723. [PubMed: 22941724]

Glassman LH, Weierich MR, Hooley JM, Deliberto TL, Nock MK. Child maltreatment, non-suicidal self-injury, and the mediating role of self-criticism. Behaviour Research and Therapy. 2007; 45(10):2483-2490. [PubMed: 17531192]

Glenn CR, Klonsky ED. A multimethod analysis of impulsivity in nonsuicidal self-injury. Personality Disorders. 2010; 1(1):67-75. [PubMed: 22448604]

Glenn CR, Klonsky ED. Nonsuicidal self-injury disorder: an empirical investigation in adolescent psychiatric patients. Journal of Clinical Child and Adolescent Psychology. 2013; 42(4):496-507. [PubMed: 23682597]

Goodman LA. On the exact variance of products. Journal of the American Statistical Association. 1960; 55:708-713.

Goodwin RD, Fergusson DM, Horwood LJ. Childhood abuse and familial violence and the risk of panic attacks and panic disorder in young adulthood. Psychological Medicine. 2005; 35(6):881890. [PubMed: 15997608]

Gunderson JG. Borderline personality disorder: ontogeny of a diagnosis. The American Journal of Psychiatry. 2009; 166(5):530-539. [PubMed: 19411380]

Jacobson CM, Gould M. The epidemiology and phenomenology of non-suicidal self-injurious behavior among adolescents: A critical review of the literature. Archives of Suicide Research. 2007; 11(2):129-147. [PubMed: 17453692]

Janis IB, Nock MK. Are self-injurers impulsive?: Results from two behavioral laboratory studies. Psychiatry Research. 2009; 169(3):261-267. [PubMed: 19758706]

Jollant F, Guillaume S, Jaussent I, Bellivier F, Leboyer M, Castelnau D, Courtet P. Psychiatric diagnoses and personality traits associated with disadvantageous decision-making. European Psychiatry. 2007; 22(7):455-461. [PubMed: 17764910]

Kessler RC. Posttraumatic stress disorder: the burden to the individual and to society. The Journal of Clinical Psychiatry. 2000; 61(Suppl 5):4-12. discussion 13-14. [PubMed: 10761674]

Kessler RC, McGonagle KA, Zhao S, Nelson CB, Hughes M, Eshleman S, Kendler KS. Lifetime and 12-month prevalence of DSM-III-R psychiatric disorders in the United States: Results from the national comorbidity survey. Archives of General Psychiatry. 1994; 51(1):8-19. [PubMed: 8279933]

Kingston S, Raghavan C. The relationship of sexual abuse, early initiation of substance use, and adolescent trauma to PTSD. Journal of Traumatic Stress. 2009; 22(1):65-68. [PubMed: 19145642]

Klonsky ED. The functions of deliberate self-injury: A review of the evidence. Clinical Psychology Review. 2007; 27(2):226-239. [PubMed: 17014942]

Klonsky ED, Muehlenkamp JJ. Self-injury: A research review for the practitioner. Journal of Clinical Psychology. 2007; 63(11):1045-1056. [PubMed: 17932985]

Lara DR, Pinto O, Akiskal K, Akiskal HS. Toward an integrative model of the spectrum of mood, behavioral and personality disorders based on fear and anger traits: I. Clinical implications. Journal of Affective Disorders. 2006; 94(1):67-87. [PubMed: 16730070]

Lewinsohn PM, Rohde P, Seeley JR. Adolescent psychopathology: III. The clinical consequences of comorbidity. Journal of the American Academy of Child \& Adolescent Psychiatry. 1995; 34(4): 510-519. [PubMed: 7751265]

MacKinnon DP, Warsi G, Dwyer JH. A simulation study of mediated effect measures. Multivariate Behavioral Research. 1995; 30(1):41-62. [PubMed: 20157641]

Monkul ES, Hatch JP, Nicoletti MA, Spence S, Brambilla P, Lacerda AL, Soares JC. Fronto-limbic brain structures in suicidal and non-suicidal female patients with major depressive disorder. Molecular Psychiatry. 2007; 12(4):360-366. [PubMed: 17389903]

Nock MK. Why do people hurt themselves? New insights into the nature and functions of self-injury. Current Directions in Psychological Science. 2009; 18(2):78-83. [PubMed: 20161092]

Nock MK, Holmberg EB, Photos VI, Michel BD. Self-injurious thoughts and behaviors interview: Development, reliability, and validity in an adolescent sample. Psychological Assessment. 2007; 19(3):309-317. [PubMed: 17845122] 
Nock MK, Joiner TE Jr, Gordon KH, Lloyd-Richardson E, Prinstein MJ. Non-suicidal self-injury among adolescents: diagnostic correlates and relation to suicide attempts. Psychiatry Research. 2006; 144(1):65-72. [PubMed: 16887199]

Patel V, Flisher AJ, Hetrick S, McGorry P. Mental health of young people: a global public-health challenge. The Lancet. 2007; 369(9569):1302-1313.

Reynolds B, Ortengren A, Richards JB, de Wit H. Dimensions of impulsive behavior: Personality and behavioral measures. Personality and individual differences. 2006; 40(2):305-315.

Rohde P, Lewinsohn PM, Seeley JR. Comorbidity of unipolar depression: II. Journal of Abnormal Psychology. 1991; 100:214-222. [PubMed: 2040773]

Sheehan DV, Sheehan KH, Shytle RD, Janavs J, Bannon Y, Rogers JE, Wilkinson B. Reliability and validity of the Mini International Neuropsychiatric Interview for Children and Adolescents (MINIKID). The Journal of Clinical Psychiatry. 2010; 71(3):313-326. [PubMed: 20331933]

Simeon D, Stanley B, Frances A, Mann JJ, Winchel R, Stanley M. Self-mutilation in personality disorders: Psychological and biological correlates. American Journal of Psychiatry. 1992; 149:221-226. [PubMed: 1734743]

Sobel ME. Asymptotic confidence intervals for indirect effects in structural equations models. Sociological methodology. 1982; 13:290-312.

Teicher MH, Andersen SL, Polcari A, Anderson CM, Navalta CP, Kim DM. The neurobiological consequences of early stress and childhood maltreatment. Neuroscience \& Biobehavioral Reviews. 2003; 27:33-44. [PubMed: 12732221]

Widom CS, DuMont K, Czaja SJ. A prospective investigation of major depressive disorder and comorbidity in abused and neglected children grown up. Archives of General Psychiatry. 2007; 64(1):49-56. [PubMed: 17199054] 


\section{Highlights}

- Adolescent nonsuicidal self-injury is a pressing public health concern.

- The pathway leading to nonsuicidal self-injury is equifinal.

- Results suggest that child abuse contributes to comorbidity, which leads to NSSI.

- Findings underscore the importance of prevention programs that reduce child abuse. 

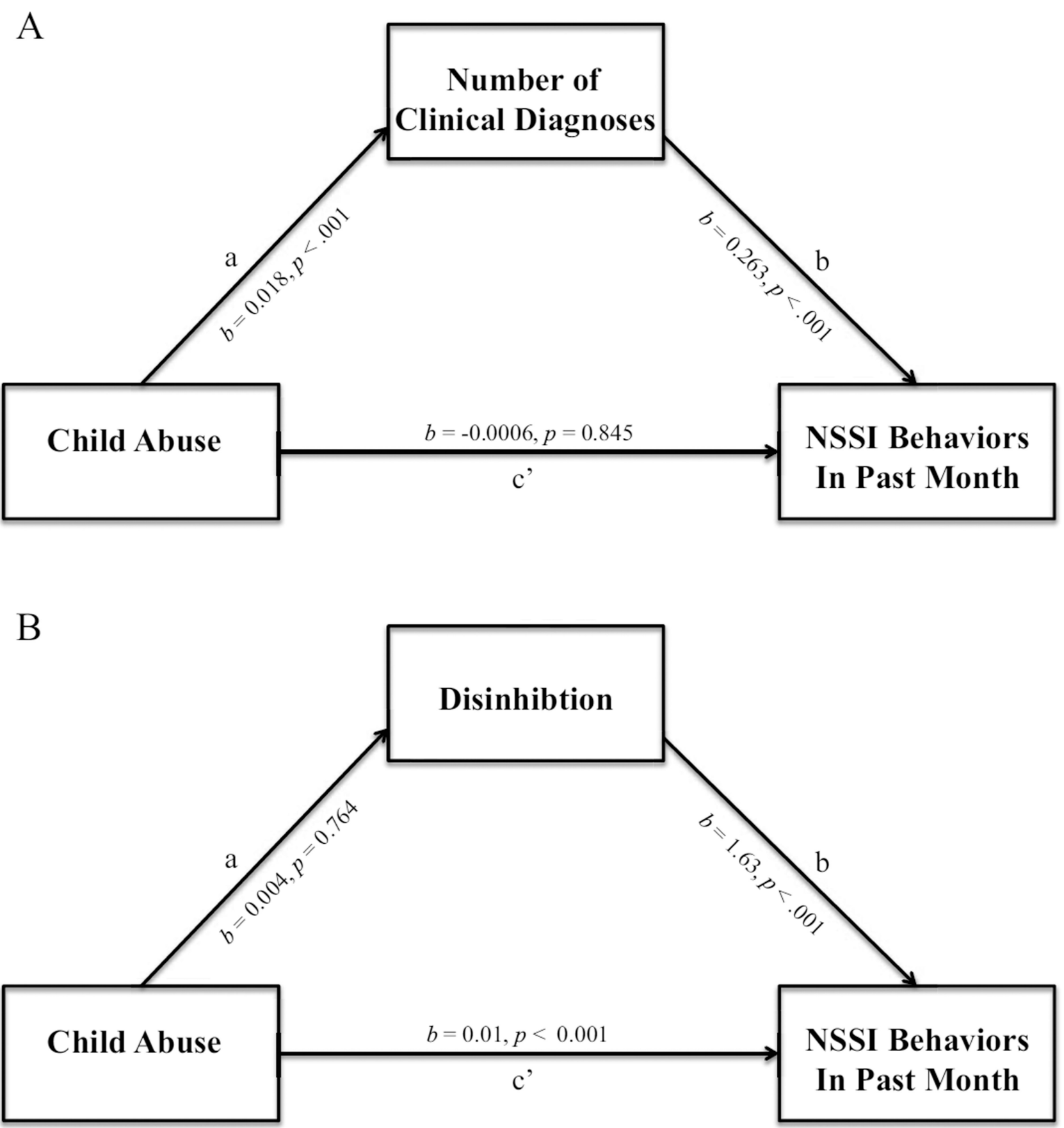

Figure 1.

Models of nonsuicidal self-injury

Note. (A) Comorbidity as a Mediator of Child Abuse and NSSI, (B) Disinhibition as

Mediator between Child Abuse and NSSI 


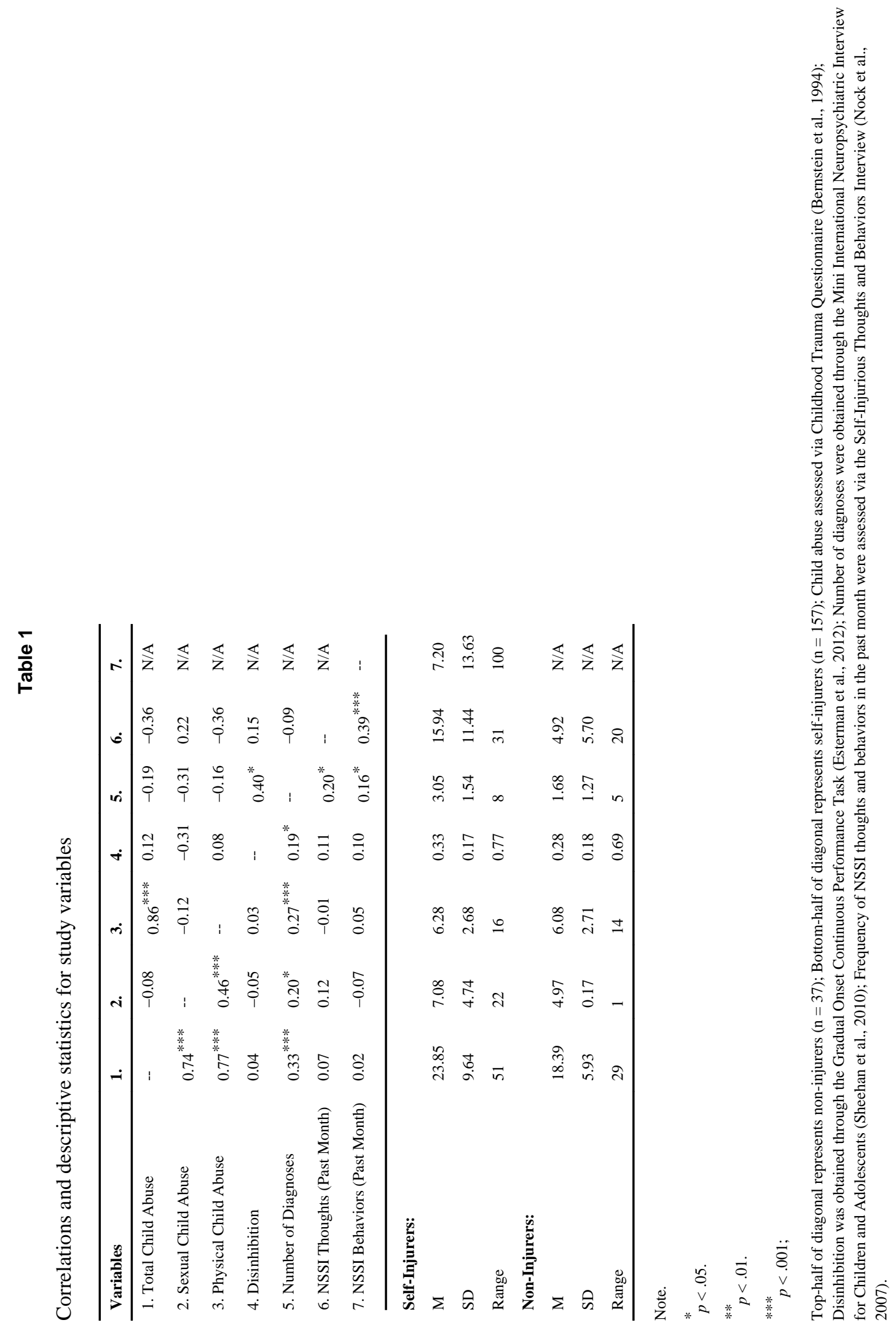


Table 3

Prevalence of psychiatric disorders among self-injurers and non-injurers

\begin{tabular}{lccc}
\hline \multicolumn{1}{c}{ Psychiatric Diagnosis } & Total & $\begin{array}{c}\text { Self-Injurers } \\
(\mathbf{n}=\mathbf{1 5 7})\end{array}$ & $\begin{array}{c}\text { Non-Injurers } \\
(\mathbf{n}=\mathbf{3 7})\end{array}$ \\
\hline Major Depressive Disorder & $98(50.52 \%)$ & $83(52.87 \%)$ & $15(40.54 \%)$ \\
Panic Disorder & $78(40.21 \%)$ & $72(45.86 \%)$ & $6(16.22 \%)$ \\
Dysthymia & $73(37.63 \%)$ & $58(36.94 \%)$ & $15(40.54 \%)$ \\
Generalized Anxiety Disorder & $63(32.47 \%)$ & $52(33.12 \%)$ & $11(29.73 \%)$ \\
Social Anxiety & $61(31.44 \%)$ & $56(35.67 \%)$ & $5(13.51 \%)$ \\
Posttraumatic Stress Disorder & $43(22.16 \%)$ & $41(26.11 \%)$ & $2(5.41 \%)$ \\
ADHD & $26(13.4 \%)$ & $23(14.65 \%)$ & $3(8.11 \%)$ \\
Substance Abuse/Dependence & $18(9.28 \%)$ & $16(10.19 \%)$ & $2(5.41 \%)$ \\
Obsessive Compulsive Disorder & $15(7.73 \%)$ & $15(9.55 \%)$ & $0(0.00 \%)$ \\
Bipolar Disorder & $10(5.15 \%)$ & $10(6.37 \%)$ & $0(0.00 \%)$ \\
Separation Anxiety & $10(5.15 \%)$ & $9(5.73 \%)$ & $1(2.70 \%)$ \\
Specific Phobia & $8(4.12 \%)$ & $8(5.10 \%)$ & $0(0.00 \%)$ \\
Alcohol Abuse/Dependence & $7(3.61 \%)$ & $7(4.46 \%)$ & $0(0.00 \%)$ \\
Mood Disorder with Psychosis & $6(3.09 \%)$ & $6(3.82 \%)$ & $0(0.00 \%)$ \\
Anorexia Nervosa & $4(2.06 \%)$ & $4(2.55 \%)$ & $0(0.00 \%)$ \\
Bulimia Nervosa & $5(2.58 \%)$ & $5(3.18 \%)$ & $0(0.00 \%)$ \\
Agoraphobia & $3(1.55 \%)$ & $3(1.91 \%)$ & $0(0.00 \%)$ \\
Oppositional Defiant Disorder & $2(1.03 \%)$ & $2(1.27 \%)$ & $0(0.00 \%)$ \\
Conduct Disorder & $1(0.52 \%)$ & $1(0.64 \%)$ & $0(0.00 \%)$ \\
Psychotic Disorder & $1(0.52 \%)$ & $0(0.00 \%)$ & $1(2.70 \%)$ \\
Tourettes Disorder & $1(0.52 \%)$ & $1(0.64 \%)$ & $0(0.00 \%)$ \\
\hline & & & \\
\hline
\end{tabular}

Note. Clinical diagnoses were obtained through administration of the Mini International Neuropsychiatric Interview for Children and Adolescents (Sheehan et al., 2010). 